\title{
Understanding College Students' Phone Call Behaviors Towards a Sustainable Mobile Health and Well-Being Solution
}

\author{
Yugyeong Kim \\ ykim180@fordham.edu / Fordham University, NY, USA \\ Sudip Vhaduri \\ svhaduri@fordham.edu / Fordham University, NY, USA \\ Christian Poellabauer \\ cpoellab@nd.edu / University of Notre Dame, IN, USA
}

Recepción: 31/10/2020 Aceptación: 4/11/2020

\begin{abstract}
AвSTRaCt. During the transition from high school to on-campus college life, students leave home and start facing enormous life changes, including meeting new people, taking on more responsibilities, being away from the family, and dealing with academic challenges. These changes lead to an elevation of stress and anxiety, affecting students' health and well-being. With the help of smartphones and their rich collection of sensors, we can continuously monitor various factors that affect students' behavioral patterns, such as communication behaviors associated with their health, well-being, and academic success. In this work, we try to assess college students' communication patterns (in terms of phone call duration and frequency) that vary across various geographical contexts (e.g., dormitories, class buildings, dining halls) during different times (e.g., epochs of a day, days of a week) using visualization techniques. The findings from this work will help foster the design and delivery of smartphone-based health interventions, thus helping the students adapt to the changes in life.
\end{abstract}

KEYWORDS: mobile health / phone call / temporal factors / geographical factors 


\title{
Comprensión de los comportamientos de los estudiantes universitarios en materia de llamadas telefónicas para una solución sostenible de salud y bienestar móvil
}

\begin{abstract}
Resumen. Durante la transición de la escuela secundaria a la vida universitaria en el campus, un estudiante deja su casa y empieza a enfrentarse a enormes cambios en su vida, como conocer gente nueva, mayores responsabilidades, estar lejos de la familia y retos académicos. Estos cambios provocan un aumento del estrés y la ansiedad, lo que afecta a la salud y el bienestar del estudiante. Con la ayuda de los smartphones y su enriquecida colección de sensores, podemos monitorizar continuamente varios factores que afectan a los patrones de comportamiento de los estudiantes, como las conductas de comunicación asociadas a su salud, bienestar y éxito académico. En este trabajo tratamos de evaluar los patrones de comunicación de los estudiantes universitarios (en términos de duración y frecuencia de las llamadas telefónicas) que varían a través de varios contextos geográficos (por ejemplo, dormitorios, clases, comedores) durante diferentes momentos (por ejemplo, épocas de un día, días de una semana) utilizando técnicas de visualización. Los resultados de este trabajo ayudarán a fomentar el diseño y la realización de intervenciones sanitarias basadas en los teléfonos inteligentes; de este modo, se ayudará a los estudiantes a adaptarse a los distintos cambios en sus vidas.
\end{abstract}

PALABRAS CLAVE: salud móvil / llamada telefónica / factores temporales / factores geográficos 


\section{INTRODUCTION}

Due to the recent advancement of technology, smartphones have become an indispensable part of our life. With the ever-increasing sensing capabilities of smartphones, we can track different spatiotemporal factors and their effect on our various behavioral patterns, such as physical activity and communication patterns, which can be used to develop predictive models and deliver interventions (Amin et al., 2009; Vhaduri et al., 2019). Similarly, with the help of smartphones' sensing capability, we can monitor college students' daily life to find factors to improve their lives. Students leave their school friends and homes for the first time when starting on-campus college life. During this transition period, students go through a stage where they may experience extreme stress, anxieties, and depression (Montoliu et al., 2013; Bogomolov et al., 2014; Vhaduri et al., 2018d) as they face many changes, such as adapting to a new lifestyle, meeting new people, and facing academic deadlines. These changes impact their mental and physical health and academic performance (Trockel et al., 2000). Therefore, a better understanding of various temporal and geographical patterns of college students' communication behaviors can help us design and deliver different smart health interventions to ensure students' health and well-being while adapting to a new lifestyle during the transition period.

In this paper, we present our analysis of college students' communication patterns (in terms of call duration and frequency/count) during various temporal contexts (e.g., epochs of a day, days of a week) in different geographical contexts using a dataset collected from a cohort of more than 400 on-campus first-year students over three consecutive semesters. This work's primary goal is to present the insights obtained from the visualization of communication patterns that vary across different contexts. This work provides a foundation for potential future strategies that aim to improve the physical and mental well-being and academic success of students who leave their home after high school to start their on-campus undergraduate studies. Furthermore, this can be utilized to design, develop, and deploy smartphone-based health interventions to help students cope with changes and challenges that they face while transitioning between school and college.

\section{DATASET}

The NetHealth mobile crowdsensing study (Vhaduri et al., 2016, 2018c, 2017c, 2017d) began at the University of Notre Dame in 2015 with over 400 on-campus freshmen (average age of 17 years and 11 months with a standard deviation of 11 months) to investigate the impacts of "always-on connectivity" on the health habits, emotional wellness, and social ties of college students over multiple semesters. All procedures were fully approved by the IRB before distribution. Students were recruited using both e-mail and Facebook invites and were given a data collection app for their iPhones (Hossain et al., 2016). The smartphone app collected data 24 hours a day. The data collected by the smartphone app included identifiers of the device's 
network connections (Wi-Fi, cellular), device state (e.g., battery charge level), screen state, geographic location, and user communications (e.g., phone calls). While some sensor data, such as Wi-Fi and cellular, are recorded at a fixed sampling frequency, other data, such as the phone call data (i.e., start time and duration), are recorded using a callback mechanism. Location data are recorded with a sampling period of 165 seconds, and they come as a series of location points. Each location point is defined as a tuple $\{\lambda, \vartheta, T\}$ (Montoliu et al., 2013), where and are the latitude and longitude of a location point, and $\mathrm{T}$ is the timestamp when the location point is recorded. While most sensor data are transmitted to a remote server during a nightly upload, other data, such as the communication data (phone calls, texts, etc.) and statistics, are transmitted via a desktop client. In this work, we used location data and phone call data that come with the time of call start, duration (measured in seconds), flags to check whether the call is answered and originated/received, and phone number on the other end.

\section{METHODOLOGY}

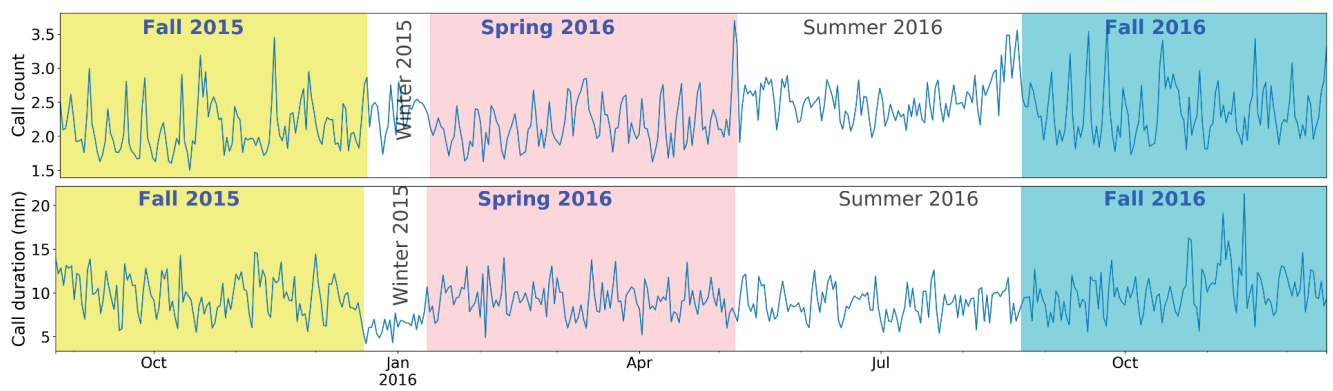

Figure 1. Time series of day-level average phone call count (top) and duration (bottom)

Own elaboration

In this paper, we intend to demonstrate the link between phone call behaviors in various temporal and geographical contexts of a cohort of on-campus first-year students. Before we describe the detailed analysis, we will first introduce phone call-related terminologies, and then the dataset and methods used in this work.

We primarily use two communication measures, namely "call count" and "call duration" (Figure 1), to assess students' communication behaviors. They are defined as below:

- Average call duration, i.e., call duration per person in a unit time (e.g., in a day), which is computed as:

$$
D^{j}=\frac{\sum_{i=1}^{n^{j}} d_{i}^{j}}{n^{j}}
$$


Where $d_{i}^{j}$ is the call duration of $i^{\text {th }}$ person in the $j^{\text {th }}$ day, $n^{j}$ is the number of active persons in the $j^{\text {th }}$ day, and $D^{j}$ is the call duration per person in the $j^{\text {th }}$ day. Finally, the call duration per person per day is the average per person call duration obtained from all days.

- Average call count, i.e., call count per person in a unit time (e.g., in a day), which is computed as:

$$
C^{j}=\frac{\sum_{i=1}^{n^{j}} c_{i}^{j}}{n^{j}}
$$

Where $c_{i}^{j}$ is the call count of $i^{\text {th }}$ person in the $j^{\text {th }}$ day, $n^{j}$ is the number of active persons in the $j^{\text {th }}$ day, and $C^{j}$ is the call count per person in the $j^{\text {th }}$ day. Finally, the call count per person per day is the average per person call count obtained from all days.

Additionally, we use different terminologies defined as below:

- Places of interest (POIs), which are the places where people either spend a significant amount of their day or frequently visit (Vhaduri et al., 2017a). For example, for an on-campus freshmen cohort, POIs can be dormitories (DM), class buildings (CL), dining halls and food courts (DI), athletic facilities (AL), as well as other indoor (OI) and outdoor (OD) places (Vhaduri et al., 2018a, 2018b).

- To better understand temporal patterns of communication behaviors, we split the entire day into four major epochs: morning $(8$ a. m. -12 p. m. or $8-12$ in 24-hour clock), afternoon (12 p. m. - 6 p. m. or 12 - 18 in 24-hour clock), evening (6 p. m. - 12 a. m. or $18-24$ in 24-hour clock) and night (12 a. m. - 7 a. m. or 0 - 7 in 24-hour clock) epochs (Vhaduri et al., 2016, 2017a).

\section{RESULTS}

This section presents a geo-temporal analysis using bubble charts, where the bubble placement in the y-axis shows the average call duration (in minutes) or count, and the size presents the standard deviation of the call duration or count. In Figure 2, we observe that the DMs are the dominant POIs where most students make more prolonged and frequent phone calls across the four epochs of a day, followed by outdoors. The result is very intuitive since students spend a significant part of their day in DMs. 


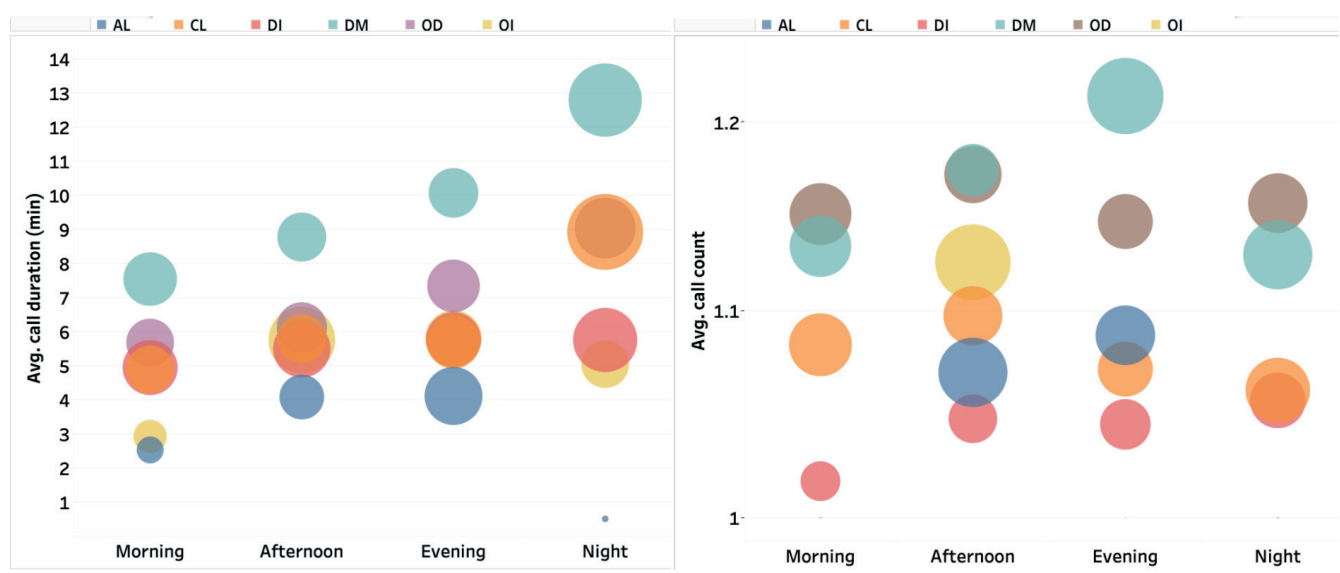

Figure 2. Bubble charts of average (a) call duration ( $\mathrm{min}$ ) (left) and (b) call count (right) across various on-campus POIs during different epochs of a day

Own elaboration

In the evening, the second highest call duration comes from outdoor POIs (ODs). We observe that, during the night, the average call duration becomes maximum. The ODs are always the second dominant group in terms of average call duration and count, and we observe a steady pattern across all epochs. In Figure 2, we observe that evening epochs at DMs achieve the highest average call count. In the figure, we further observe that students make shorter and more frequent calls in the evenings while making longer and less regular calls at nights, particularly in DMs. Additionally, the standard deviation is higher at night, which shows that call duration varies significantly across individuals during this epoch.

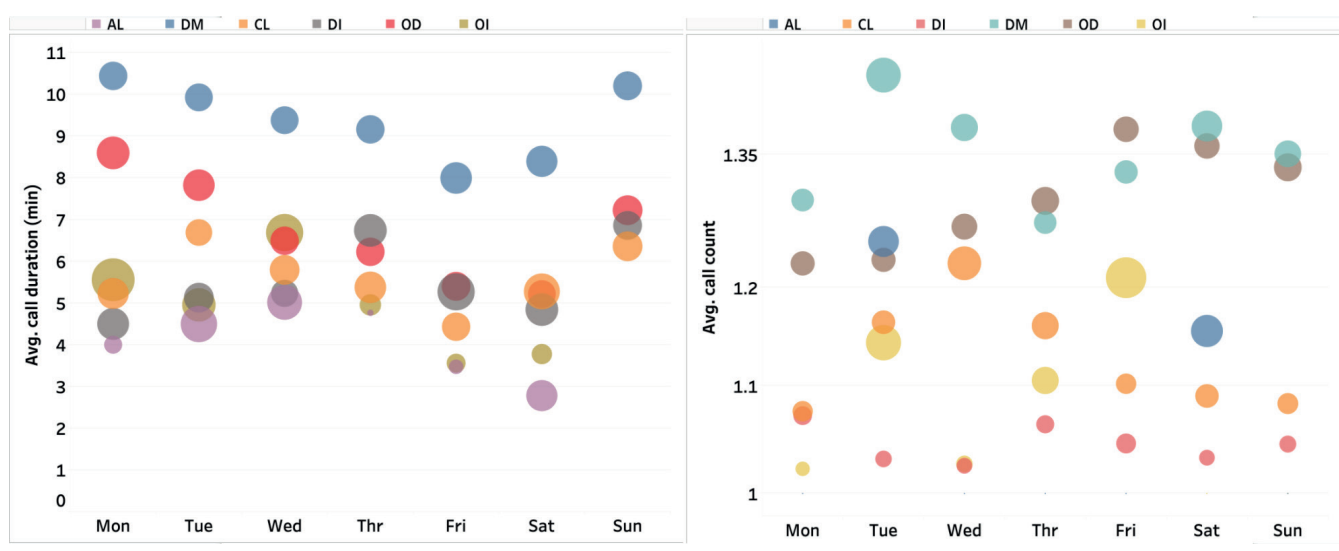

Figure 3. Bubble charts of average (a) call duration ( $\mathrm{min}$ ) (left) and (b) call count (right) across various on-campus POIs during different days of a week

Own elaboration 
In Figure 3, we find that DMs are the dominating POIs for both call duration and count across the seven days of a week. In the figure, we observe that the average call duration at DMs is significantly higher than at any other POIs. ODs are the next dominating POI in terms of average call duration. Call duration in athletic POIs (ALs) is extremely low across all days of a week with very high standard deviations. Other indoor POIs (OIs) reach the highest on Sundays because OIs include the university churches. Since primary mass is held on Sunday, a higher duration on Sunday is expected.

\section{CONCLUSIONS}

To the best of our knowledge, this is the first work that investigates the change of communication behaviors during various temporal contexts and different geographical contexts using objective smartphone data collected from a cohort of more than 400 on-campus freshmen over three consecutive semesters. We found that students make longer and less frequent calls on Sundays and Mondays compared to the other days when they make shorter and more frequent calls. This work provides a foundation for potential future strategies to develop mobile health interventions that aim at improving the physical and mental well-being, as well as the academic success of students who leave their home after high school to start their college studies. This work has some limitations, which we plan to address in the future: we plan to perform a more detailed analysis of college students' communication patterns across different geographical and temporal contexts using detailed visualization and statistical tests.

\section{REFERENCES}

Bogomolov, A., Lepri, B., Ferron, M., Pianesi, F., \& Pentland, A. (2014, November). Daily stress recognition from mobile phone data, weather conditions and individual traits. ACM international conference on Multimedia.

Diener, E., Wirtz, D., Tov, W., Kim-Prieto, C., Choi, D. W., Oishi, S., \& Biswas-Diener, R. (2010). New well-being measures: Short scales to assess flourishing and positive and negative feelings. Social indicators research, 97(2), 143-156.

Garett, R., Liu, S., \& Young, S. D. (2017). A longitudinal analysis of stress among incoming college freshmen. Journal of American college health, 65(5), 331-338.

Montoliu, R., Blom, J., \& Gatica-Perez, D. (2013). Discovering places of interest in everyday life from smartphone data. Multimedia tools and applications, 62(1), 179-207.

Trockel, M. T., Barnes, M. D., \& Egget, D. L. (2000). Health-related variables and academic performance among first-year college students: Implications for sleep and other behaviors. Journal of American college health, 49(3), 125-131. 
Vhaduri, S., Van Kessel, T., Ko, B., Wood, D., Wang, S., \& Brunschwiler, T. (2019, June). Nocturnal cough and snore detection in noisy environments using smartphonemicrophones. In International Conference on Healthcare Informatics.

Vhaduri, S., \& Poellabauer, C. (2017a). Hierarchical cooperative discovery of personal places from location traces. IEEE Transactions on Mobile Computing, 17(8), 1865-1878.

Vhaduri, S., \& Poellabauer, C. (2018a). Opportunistic discovery of personal places using multi-source sensor data. IEEE Transactions on Big Data.

Vhaduri, S., \& Poellabauer, C. (2016). Design and implementation of a remotely configurable and manageable well-being study. In Smart City 360. Springer, Cham.

Vhaduri, S., \& Poellabauer, C. (2017b). Design factors of longitudinal smartphone-based health surveys. Journal of Healthcare Informatics Research, 1(1), 52-91.

Vhaduri, S., \& Poellabauer, C. (2018b, June). Opportunistic discovery of personal places using smartphone and fitness tracker data. In IEEE Conference on Healthcare Informatics.

Vhaduri, S., \& Poellabauer, C. (2018c). Biometric-based wearable user authentication during sedentary and non-sedentary periods. arXiv preprint arXiv:1811.07060.

Vhaduri, S., \& Poellabauer, C. (2017c, August). Towards reliable wearable-user identification. In IEEE International Conference on Healthcare Informatics (ICHI).

Vhaduri, S., \& Poellabauer, C. (2016). Cooperative discovery of personal places from location traces. In International Conference on Computer Communication and Networks.

Vhaduri, S., et al. (2018d, March). Impact of different pre-sleep phone use patterns on sleep quality. In International Conference on Wearable \& Implantable Body Sensor Network.

Al Amin, M. T., Barua, S., Vhaduri, S., et al. (2009, June). Load aware broadcast in mobile ad hoc networks. In IEEE International Conference on Communications.

Hossain, A., \& Poellabauer, C. (2016, October). Challenges in building continuous smartphone sensing applications. In IEEE Conference on Wireless and Mobile Computing, Networking and Communications.

Vhaduri, S., Poellabauer, C., Striegel, A., Lizardo, O., \& Hachen, D. (2017d, August). Discovering places of interest using sensor data from smartphones and wearables. In IEEE SmartWorld, Ubiquitous Intelligence \& Computing. 